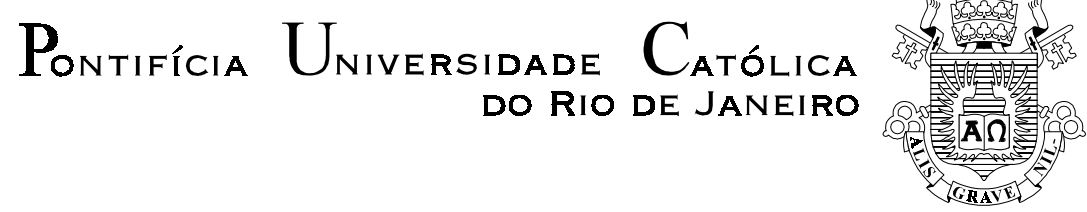

Fábio Carvalho Leite

\title{
1891: A Construção da Matriz Político- Institucional da República no Brasil
}

Dissertação apresentada como requisito parcial para obtenção do grau de Mestre pelo Programa de Pósgraduação em Direito Constitucional e Teoria do Estado do Departamento de Direito da PUC-Rio.

Orientadora: Prof. ${ }^{a}$ Ana Lúcia de Lyra Tavares Co-orientador: Prof. Adriano Pilatti 


$$
\begin{array}{r}
\text { Pontifícia Universidade Católica } \\
\text { do Rio de Janeiro }
\end{array}
$$

Fábio Carvalho Leite

\title{
1891: A Construção da Matriz Político- Institucional da República no Brasil
}

Dissertação apresentada como requisito parcial para obtenção do grau de Mestre pelo Programa de Pós-graduação em Direito Constitucional e Teoria do Estado do Departamento de Direito do Centro de Ciências Sociais da PUC-Rio. Aprovada com nota de louvor pela Comissão Examinadora abaixo assinada.

\author{
Prof. ${ }^{a}$ Ana Lúcia de Lyra Tavares \\ Orientadora \\ Departamento de Direito - PUC-Rio
}

Prof. Adriano Pilatti

Co-orientador

Departamento de Direito - PUC-Rio

Prof. José Ribas Vieira

Departamento de Direito - PUC-Rio

Prof. Paulo Braga Galvão

Departamento de Direito - UERJ

Prof. Zélia Milanez Lossio e Seiblitz

Coordenadora Setorial do Centro de Ciências Sociais - PUC-Rio

Rio de Janeiro, setembro de 2003 
Todos os direitos reservados. É proibida a reprodução total ou parcial do trabalho sem autorização da universidade, do autor e do orientador.

Fábio Carvalho Leite

Graduou-se em Direito na Pontifícia Universidade Católica do Rio de Janeiro (PUC-Rio) em 1999. É professor e coordenador de Direito Constitucional da PUC-Rio.

Ficha Catalográfica

Leite, Fábio Carvalho

1891: a construção da matriz político-institucional da república no Brasil/ Fábio Carvalho Leite; orientadora: Ana Lúcia de Lyra Tavares; co-orientador: Adriano Pilatti. - Rio de Janeiro: PUC, Departamento de Direito, 2003.

v., 218 f.; $29,7 \mathrm{~cm}$

1. Dissertação (mestrado) - Pontifícia Universidade Católica do Rio de Janeiro, Departamento de Direito.

Inclui referências bibliográficas.

1. Direito - Teses. 2. 


\section{AGRADECIMENTOS}

\section{"Uma pesquisa sem agradecimentos é suspeita."}

Umberto Eco

À professora Ana Lucia de Lyra Tavares, exemplo de dedicação à vida acadêmica que tanto inspira a nós outros, eternos amadores, pela confiança - que me trouxe até aqui -, e pelo estímulo - que me faz seguir adiante.

Ao Professor Adriano Pilatti, com quem, em um momento feliz da vida, selei uma amizade que jamais conheceu a dúvida, pelo apoio intelectual, profissional e mesmo emocional, nos não raros momentos de dificuldade. A esta já sólida - embora não tão velha - amizade devo muito do que está presente neste trabalho...e, justiça seja feita, do que não está também.

Ao Professor Luís Eduardo Melin, ser humano de qualidades excepcionais que ultrapassam os meus elogios. Nossa amizade, um belo gesto do destino, consolidouse ao longo do curso de mestrado e a ele agradeço pelas conversas que respondem por muitas das idéias contidas neste trabalho.

Ao Professor Gustavo Senechal, que, durante o período de elaboração deste trabalho, abusou flagrantemente do direito de ser amigo. Não apenas foi compreensivo com relação às minhas ausências junto à Assessoria Jurídica da Reitoria da PUC-Rio como ainda estimulou o desenvolvimento desta dissertação e, ao cabo, de uma vida acadêmica.

Aos meus amigos - grandes irmãos.

Às minhas irmãs Carla e Flávia - amigas insuperáveis.

Aos meus queridos pais Albano e Deolinda, por tudo isso. 


\title{
Resumo
}

Leite, Fábio Carvalho. 1891: a construção da matriz políticoinstitucional da República no Brasil. Rio de Janeiro, 2003. 218p. Dissertação de Mestrado - Departamento de Direito, Pontifícia Universidade Católica do Rio de Janeiro.

\begin{abstract}
A presente dissertação pretende abordar a construção da matriz político-institucional da República no Brasil, a partir do estudo das causas que levaram ao advento da República em 1889 e suas conseqüências na ordem constitucional do País.

Desse modo, o trabalho pretende identificar o projeto político representado pela Constituição de 1891 bem como investigar como este projeto foi defendido, a partir do estudo das decisões proferidas pelo Supremo Tribunal Federal.
\end{abstract}

\section{Palavras-chave}

\author{
Brasil; história; república; republicanismo; constituição; \\ constitucionalismo.
}




\section{Abstract}

Leite, Fábio Carvalho. 1891: a construção da matriz políticoinstitucional da República no Brasil. Rio de Janeiro, 2003. 218p. Dissertação de Mestrado - Departamento de Direito, Pontifícia Universidade Católica do Rio de Janeiro.

The present work intends to analyze the building of the political framework of Brazil's republican institutions, through the study of the causes to the Republic advent in 1889 and its consequences to Brazilian constitutional order.

In this way, the work aims to identify the political project represented by the Constitution of 1891 and to investigate how that project was defended, through the study of the Supreme Court decisions.

\section{Keywords}

Brazil; history; republic; republicanism; constitution; constitutional law. 


\section{SUMÁRIO}

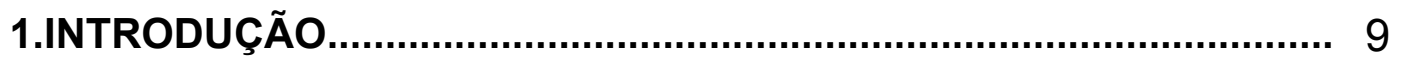

2. A República no Império............................................................... 11

2.1 A idéia republicana nos primeiros anos do Império....................... 11

2.2 A República na segunda metade do século XIX......................... 14

2.2.1 Quadro Econômico, Social e Político.................................. 14

a) Quadro Econômico.......................................................... 14

b) Quadro Social................................................................... 20

c) Quadro Político.......................................................................... 25

2.2.2 O Movimento Republicano e a Queda da Monarquia........... 31

3. A Organização Constitucional da República..................................... 47

3.1 O Governo Provisório e o Processo Constituinte.......................... 47

3.2 O Congresso Constituinte....................................................... 56

3.2.1 A Organização dos Trabalhos............................................ 56

3.2.2 Os Debates na Constituinte............................................... 63

3.2.2.1 Direito de Secessão.............................................. 68

3.2.2.2 Discriminação de rendas......................................... 68

3.2.2.3 Forças Armadas................................................... 72

3.2.2.4 Intervenção Federal.............................................. 76

3.2.2.5 Organização dos Poderes....................................... 77

3.2.2.5.1 Poder Legislativo...................................... 79

a) Composição.................................................... 79

b) Competência legislativa..................................... 82

c) Estado de sítio................................................... 83

d) Revisão constitucional........................................ 83 
3.2.2.5.2 Poder Executivo....................................... 85

a) Mandato presidencial.......................................... 85

b) Eleição........................................................ 86

c) Competências............................................... 89

d) Veto presidencial............................................ 92

e) Ministros de Estado........................................... 93

3.2.2.5.3 Poder Judiciário........................................ 94

3.2.2.6 Funcionalismo Público............................................ 96

3.2.2.7 Autonomia Municipal.......................................... 99

3.2.2.8 Declaração de Direitos - "Liberdade de Profissão".... 101

3.3 Comentários ao Processo Constituinte....................................... 102

4. O Projeto Político da Constituição de 1891 .................................... 106

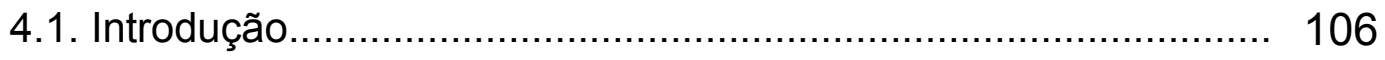

4.2. A Organização Federal...................................................... 108

4.2.1 Disposições Preliminares............................................... 108

4.2.2 Organização dos Poderes................................................ 117

4.2.2.1 Poder Legislativo.................................................. 120

4.2.2.2 Poder Executivo................................................. 124

4.2.2.3 Poder Judiciário.................................................... 136

4.3 Dos Estados.......................................................................... 140

4.4 Dos Municípios..................................................................... 141

4.5. Dos Cidadãos Brasileiros...................................................... 142

4.5.1 Das Qualidades do Cidadão Brasileiro............................... 144

4.5.2 Declaração de Direitos........................................................ 144

4.6 Disposições Gerais............................................................... 148

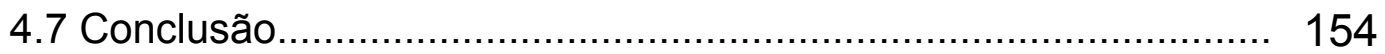


5. A Constituição de 1891 e 0 Controle de Constitucionalidade........................................................................... 155

5.1. O STF e a Guarda da Constituição............................................ 155

5.2. As Questões Mais Recorrentes.............................................. 168

5.2.1 Estado de Sítio.............................................................. 170

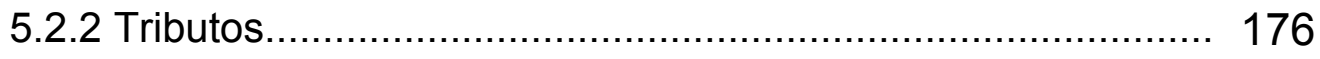

5.2.3 Direitos Políticos.......................................................... 189

5.2.4 Garantias da Magistratura.......................................... 204

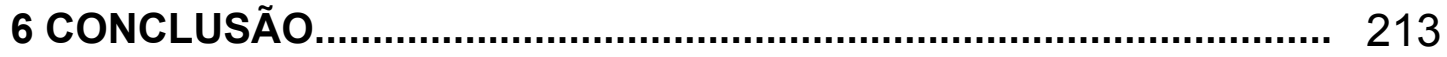

7 BIBLIOGRAFIA 